\title{
Modification of Surface Morphology of UHMWPE for Biomedical Implants
}

Ahmet Oztarhan ${ }^{1}$, Emel Sokullu Urkac ${ }^{1}$, Nusret Kaya ${ }^{1}$, Mesut Yenigul ${ }^{2}$, Funda Tihminlioglu ${ }^{3}$, Ayhan Ezdesir ${ }^{4}$, Robert Zimmerman ${ }^{5}$, Satilmis Budak ${ }^{5}$, C Muntele ${ }^{5}$, Bopha Chhay ${ }^{5}$, Daryush $\mathrm{Ila}^{5}$, Efim Oks ${ }^{6}$, Alexey Nikolaev ${ }^{6}$, Zekai Tek ${ }^{7}$, and Rengin Eltem $^{1}$

${ }^{1}$ Bioengineering, Ege University, Bornova, Izmir, 35100, Turkey

${ }^{2}$ Chemical engineering, Ege University, Bornova, Izmir, 35100, Turkey

${ }^{3}$ Chemical engineering, Izmir Institute of Technology, Izmir, 35000, Turkey

${ }^{4}$ Petkim, Izmir, 35000, Turkey

${ }^{5}$ Alabama A\&M University, Huntsville, AL, 35762

${ }^{6}$ High Current Electronics Institute, Tomsk, 634055, Russian Federation

${ }^{7}$ Celal Bayar University, Manisa, 45000, Turkey

\begin{abstract}
Ultra High Molecular Weight Polyethylene (UHMWPE) samples were implanted with metal and metal-gas hybrid ions $(\mathrm{Ag}, \mathrm{Ag}+\mathrm{N}, \mathrm{C}+\mathrm{H}, \mathrm{C}+\mathrm{H}+\mathrm{Ar}, \mathrm{Ti}+\mathrm{O})$ by using improved MEVVA Ion implantation technique [1,2] . An extraction voltage of $30 \mathbf{~ k V}$ and influence of 1017 ions/cm2 were attempted in this experiment. to change their surface morphologies in order to understand the effect of ion implantation on the surface properties of UHMWPEs. Characterizations of the implanted samples with RBS , ATR - FTIR, spectra were compared with the un-implanted ones. Implanted and unimplanted samples were also thermally characterized by TGA and DSC. It was generally observed that $\mathrm{C}-\mathrm{H}$ bond concentration seemed to be decreasing with ion implantation and the results indicated that the chain structure of UHMWPE were changed and crosslink density and polymer crystallinity were increased compared to unimplanted ones resulting in increased hardness. It was also observed that nano size cracks (approx.10nm) were significantly disappeared after Ag implantation, which also has an improved antibacterial effect. Contact angle measurements showed that wettability of samples increased with ion implantation. Results showed that metal and metal+gas hybrid ion implantation could be an effective way to improve the surface properties of UHMWPE to be used in hip and knee prosthesis.
\end{abstract}

\section{Introduction}

Ultra High Molecular Weight Polyethylene (UHMWPE) has been commonly used for acetabular cup of total hip joint replacement as it has densely packed linear polyethylene chains, which gives improved mechanical properties. However the wear of UHMWPE against the articulating metal part and wear debris generated at the surface is recognized as the major cause of loosening and failure of the total joint replacement. Recent studies show that increasing the cross-linking in the polyethylene significantly reduces wear leading to more durable acetabular components and increasing the lifetime of an implant . Increasing the cross-link density of UHMWPE in which UHMWPE is irradiated in air at an elevated temperature with a high-dose-rate electron beam or a common approach is 
to cross-link the polymer by gamma irradiation, which improves markedly the wear resistance of the polymer but with changed bulk properties [3]. In this work, we tried to change the surface morphology of UHMWPE by low energy metal and metal+gas hybrid ion implantation by MEVVA, with an expectation of improving surface mechanical properties, and promoting antibacterial effect without changing the bulk properties of UHMWPE .

\section{Experimental}

Samples with medical grade GUR 1020 - Type 1 - Ultra High Molecular Weight Polyethylene (UHMWPE - , Hipokrat Co.) with a density of $945 \mathrm{~kg} / \mathrm{m}^{3}$ were used . Disk samples with a diameter of $30 \mathrm{~mm}$ and thickness of $4 \mathrm{~mm}$ were polished down to about surface roughness of $95(\mathrm{~nm}) \mathrm{Ra}$. Samples were implanted with $\mathrm{Ag}, \mathrm{Ag}+\mathrm{N}, \mathrm{C}+\mathrm{H}$, $\mathrm{C}+\mathrm{H}+\mathrm{Ar}, \mathrm{Ti}+\mathrm{O}$ ions by using MEVVA ion implanter with a fluence of $10^{17} \mathrm{ion} / \mathrm{cm}^{2}$ and extraction voltage of $30 \mathrm{kV}$. ATR- FTIR chemical characterization analysis was used to see if any new chemical bonds formed 2 microns deep at the surface. Thermo Nicolet Nexus 670 model FTIR with Smart DuraSampllR 3 Bounce diamond HATR (3 reflection diamond ATR) and OMNIC software were used. DSC (Differential Scanning Calorimeter) SHIMADZU DT-50 and the TGA (Thermo Gravimetric Analyzer) SHIMADZU DT-51 were used for thermal analysis of implanted and unimplanted samples. The analyses were performed in a dry nitrogen atmosphere. Aluminum cells were used for analysis of the polymers. The temperatures of the sample cells were increased by $10^{\circ} \mathrm{C} / \mathrm{min}$. The total heat of melting $\Delta H$ (the area under the endothermDSC) was determined and, knowing the total heat of fusion of $100 \%$ crystalline UHMWPE $\left(\Delta H_{\mathrm{f}}=293.6 \mathrm{~J} / \mathrm{g}\right)$, the percentage crystallinity was calculated as $100\left(\Delta H / \Delta H_{\mathrm{f}}\right)$ [4]. Scanning electron microscopy (Philips XL-305 FEG - SEM) was used to examine the surfaces of unimplanted and $\mathrm{Ag}$ and $\mathrm{Ag}+\mathrm{N}$ implanted samples. Atomic force microscopy (AFM) was used to investigate the surface morphology of unimplanted and implanted UHMWPE. A Digital Instrument- MultiModeSPM apparatus was used to determine the surface roughness. The durometer hardness test was used to measure the relative hardness of the samples. The test method is based on the penetration of a specified indenter forced into the material under specified conditions. A Shore hardness tester ZWICk/Roell (HPE) under $50 \mathrm{~N}$ force was used. The contact angle of wateron unimplanted and implanted UHMWPE surfaces was measured with a Krüss-G10 goniometer. The antibacterial activities of unimplanted and Ag implanted UHMWPE samples of 5mm diameter and 3mm thickness were examined against "Staphylococcus Aureus" by "Agar Disk Diffusion Method". After 24 hours bacteria reduction was 100\%.

\section{Results and Discussions}

RBS graphs, are used as an analytical tool to measure some of the implanted elements (C, Ag, Ti, N, O) concentration of the sample surfaces. For example, Figure 1,2 show $\mathrm{Ag}, \mathrm{Ti}, \mathrm{C}, \mathrm{N}$ and $\mathrm{O}$ ions, which can be detected up to $42+15 \mathrm{~nm}$ underneath the surface. All spectra show an $\mathrm{O}$ peak, which is believed to be caused by oxidation and some small peaks by the residual air in the Vacuum chamber. Oxygen uptake takes place once the ion bombarded polymer sample was exposed to the air [5]. 


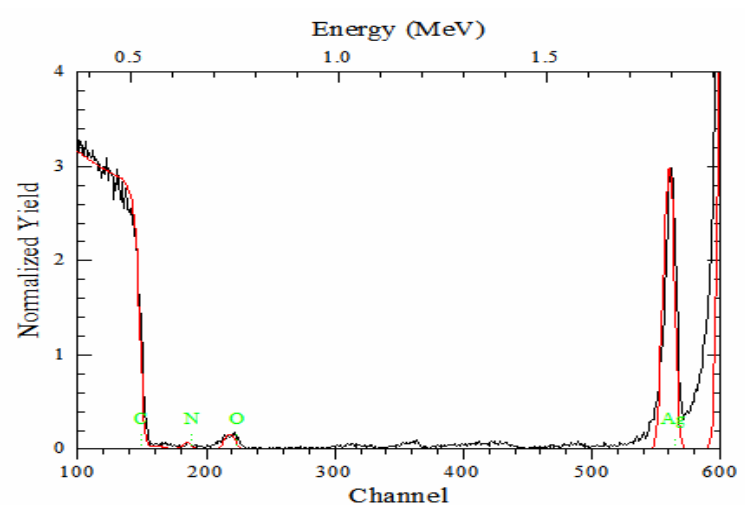

Figure.1 RBS Spectrum of Ag $+\mathrm{N}$ Implanted UHMWPE

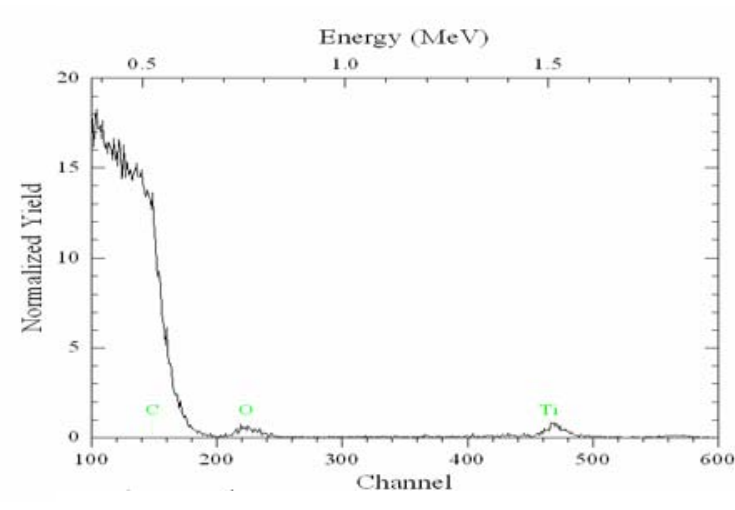

Figure.2 RBS Spectrum of $\mathrm{Ti}+\mathrm{O}$ Implanted UHMWPE

The characteristic absorption bands for the $\mathrm{CH}_{2}$ bonds appear in the 2900-2840, 1460-1370 and 740-720 $\mathrm{cm}^{-1}$ regions [6]. The transmission ATR analysis of the unimplanted and implanted samples confirms the $\mathrm{C}-\mathrm{H}$ bond breaking since the $\mathrm{C}-\mathrm{H}$ stretching (at $2847 \mathrm{~cm}^{-1}$ ) bond peaks of the pure UHMWPE sample disappear after ion implantation (figures. $3,4,5$ ).

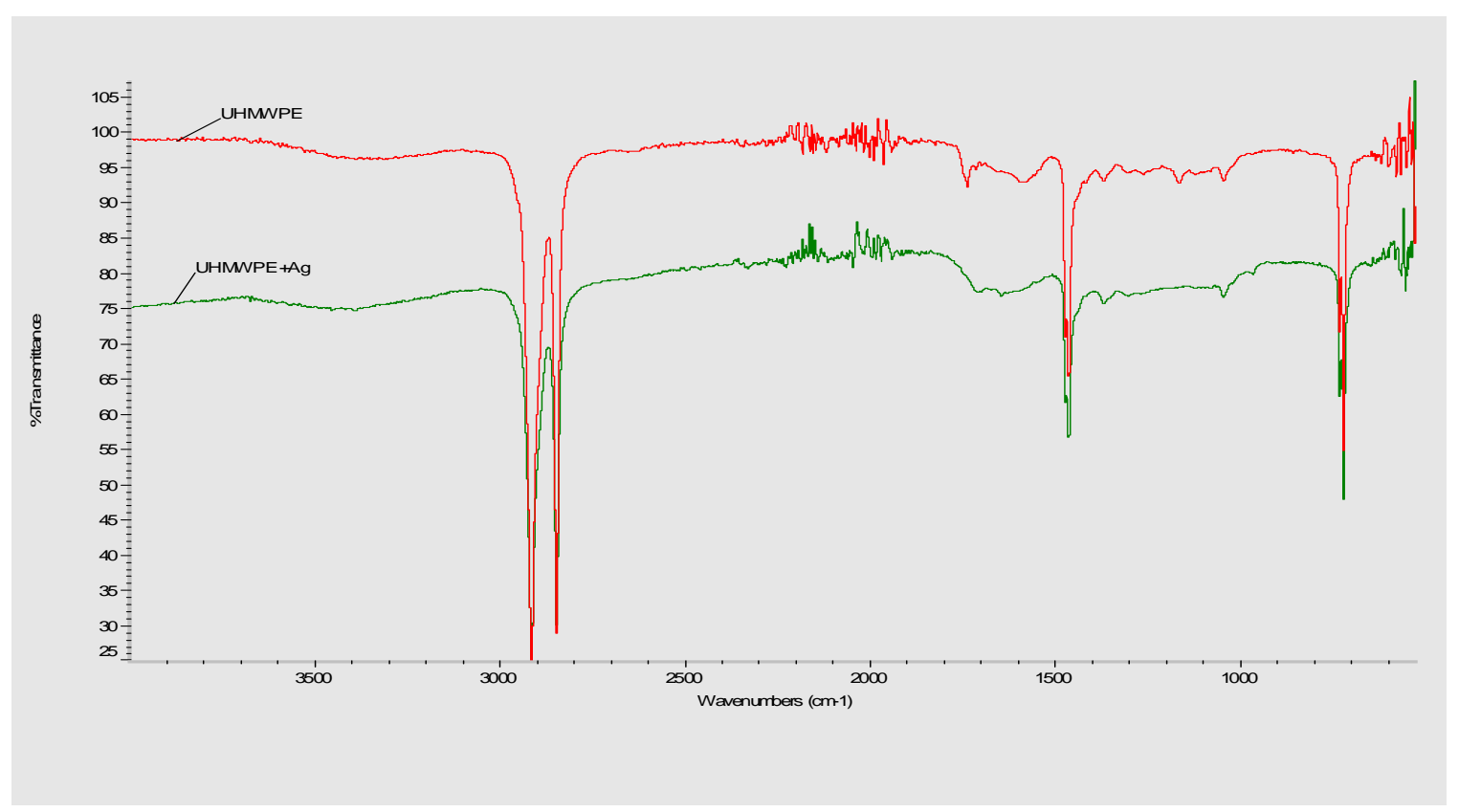

Figure.3 FTIR spectra of Ag Implanted UHMWPE 


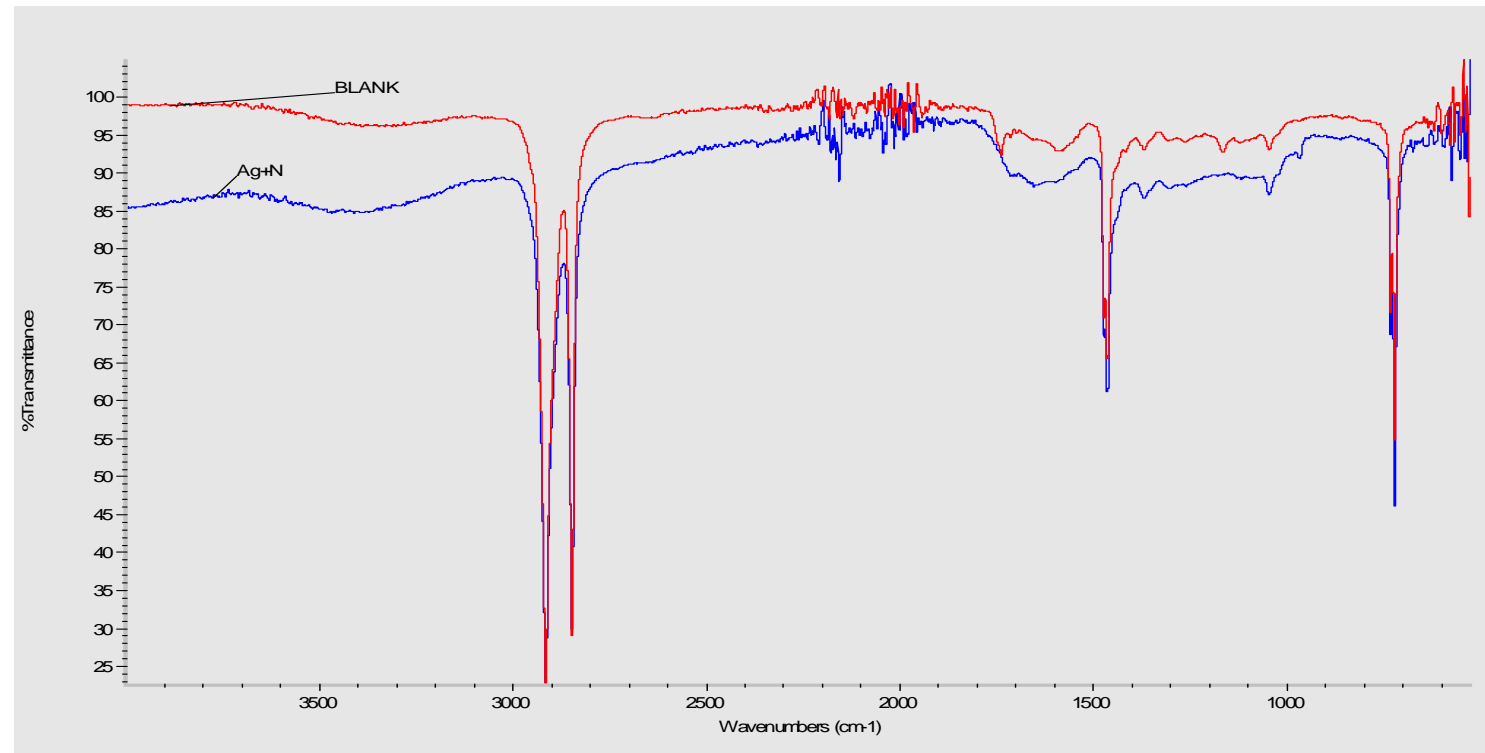

Figure.4 FTIR spectra of Ag+N Implanted UHMWPE

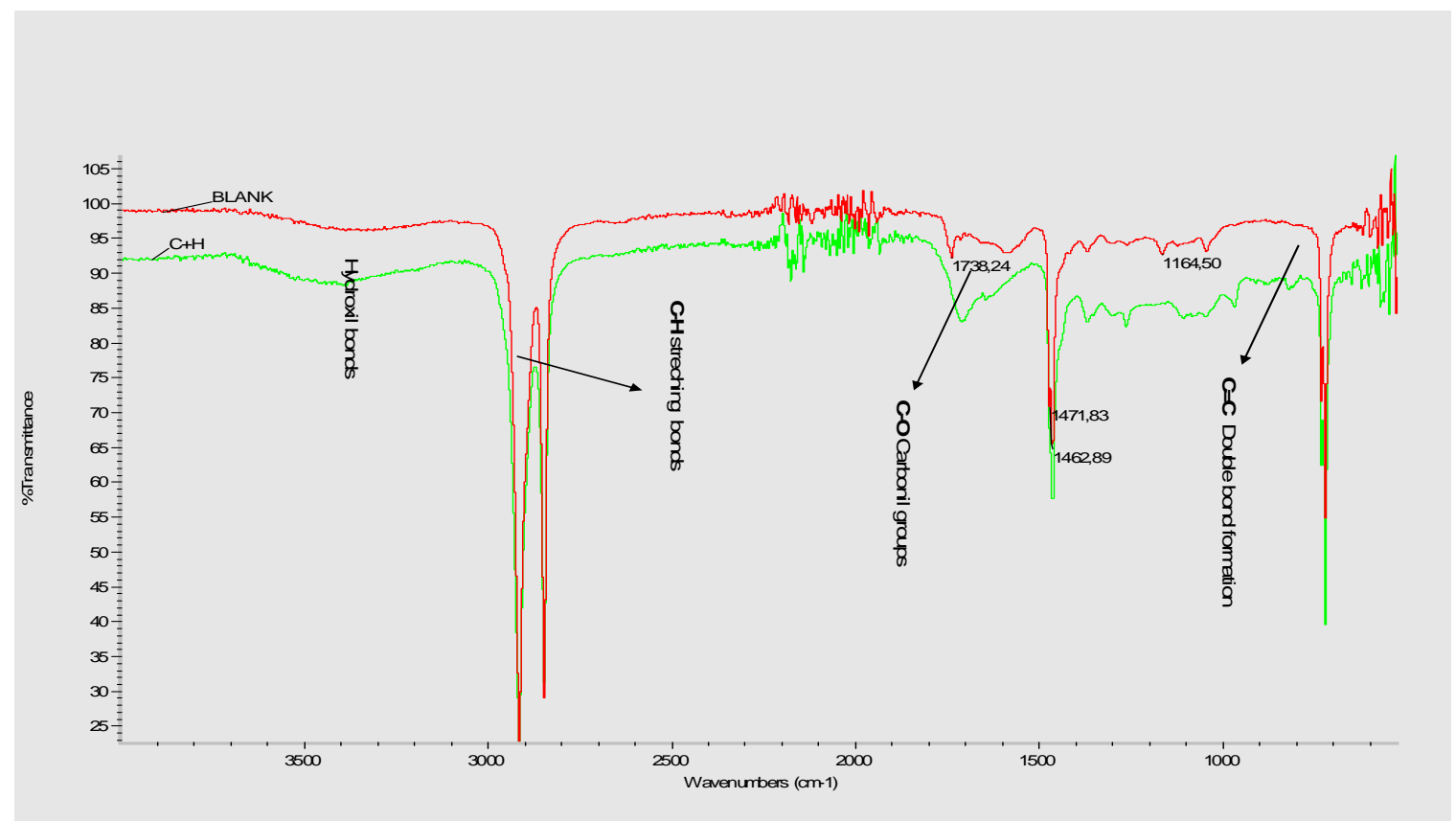

Figure.5 FTIR spectra of $\mathrm{C}+\mathrm{H}$ Implanted UHMWPE

Increase in the absorption bands in the 800 and $1738.4 \mathrm{~cm}^{-1}$ regions, due to the implantation, has been attributed to the creation of unsaturated $\mathrm{C}=\mathrm{C}$ bonds and carbonyl group formations respectively [7]. One of the main products of the ion bombardment is the chemical change resulting the $\mathrm{C}=\mathrm{C}$ formation, and its stretching vibration is clearly 
observed in the spectra by an absorbance peak at $800 \mathrm{~cm}^{-1}$. The presence of this peak suggests that after ion implantation, the polymer surface becomes poor of hydrogen and rich of unsaturation which is susceptible to crosslinking and oxidation. Oxidation causes carbonyl groups formation which is observed at around $1740 \mathrm{~cm}^{-1}$. DSC (Differential Scanning Calorimeter) was used to measure the energy change of the polymer by increasing the temperature in inert $\mathrm{N}_{2}$ gas atmosphere. DSC determines thermal properties of the polymer such as $\mathrm{T}_{\mathrm{m}}, \Delta \mathrm{H}_{\text {fus }} . \Delta \mathrm{H}_{\text {fus }}$ is defined as the fusion enthalpy which is calculated by taking an integration of the area of the melting peak. The crystallinity of UHMWPE (unimplanted and implanted) percentage is shown in table.1, tohether with roughness, hardness, contact angle, $\Delta \mathrm{H}_{\text {fus }}$ and $\mathrm{T}_{\mathrm{m}}$. The detailed calculation of the crystallinity percentage of the polymer could be found in the literature [4] . DSC Analysis of un implanted UHMWPE, $\mathrm{Ag}$ and $\mathrm{Ag}+\mathrm{N}$, and $\mathrm{C}+\mathrm{H}+\mathrm{Ar}$ and $\mathrm{C}+\mathrm{H}$ ion implanted UHMWPE samples are shown in figures 6 and 7.

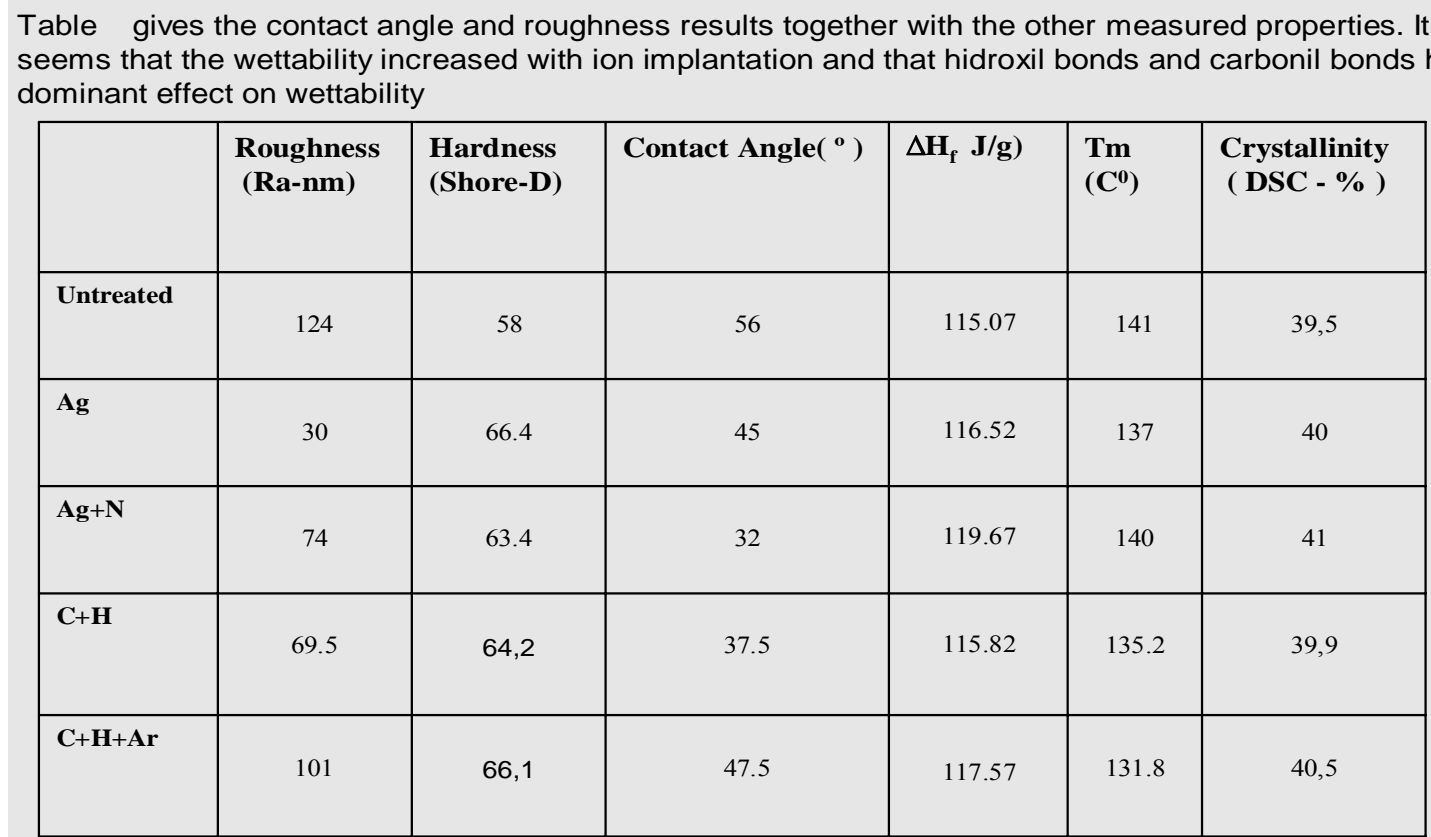

Table 1. Over all results

Table.1 Over all results 


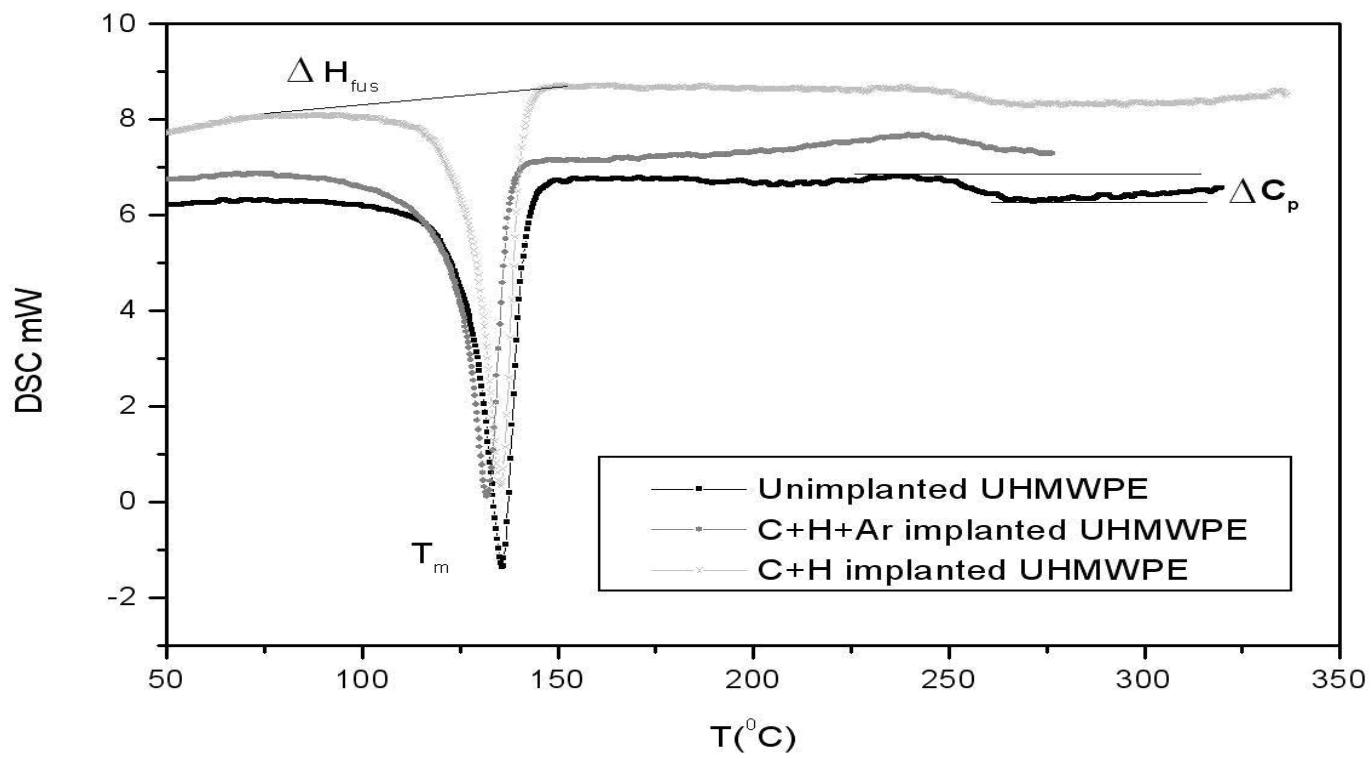

Figure .6. DSC Analysis of unimplanted UHMWPE, $\mathrm{C}+\mathrm{H}+\mathrm{Ar}$ and $\mathrm{C}+\mathrm{H}$ ion implanted UHMWPE samples.

TGA

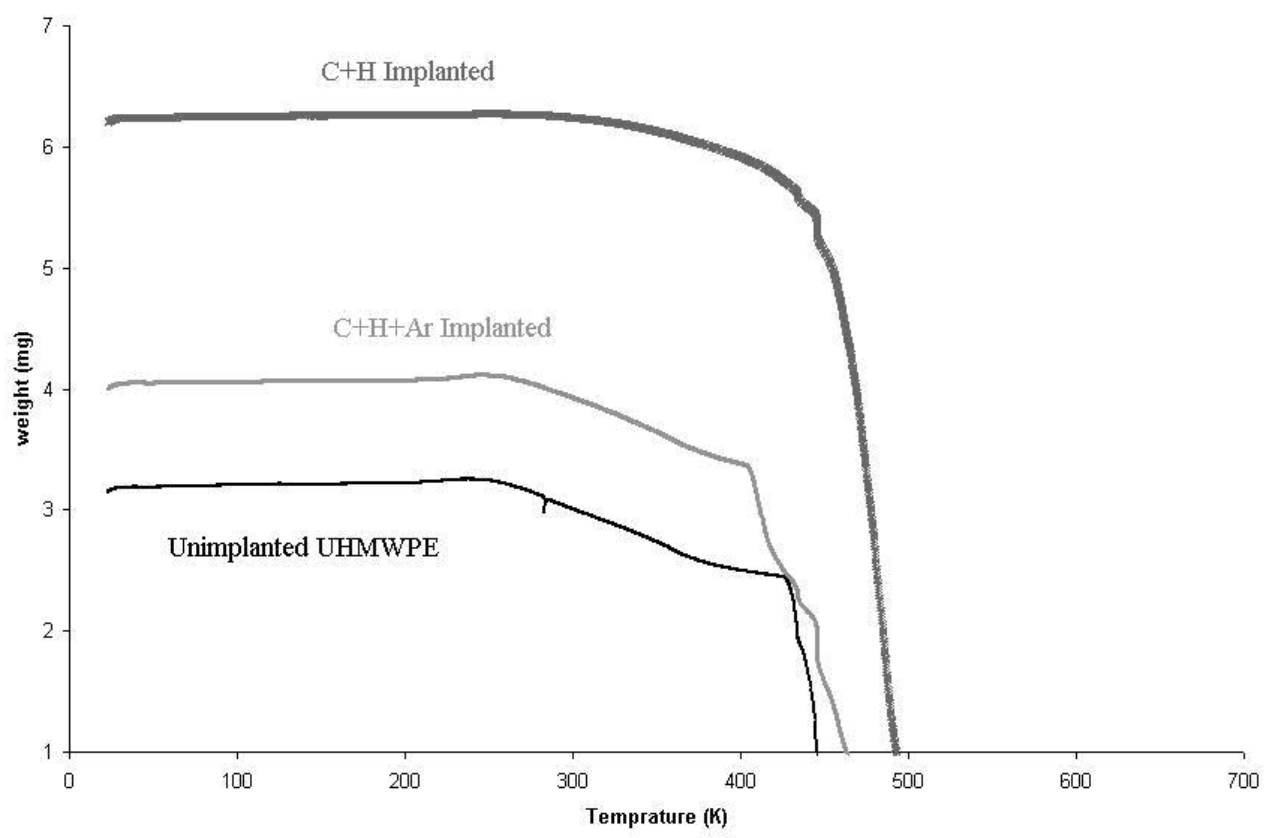

Figure .7. DSC Analysis of Untreated, $\mathrm{Ag}$ and $\mathrm{Ag}+\mathrm{N}$ Implanted UHMWPE Samples 


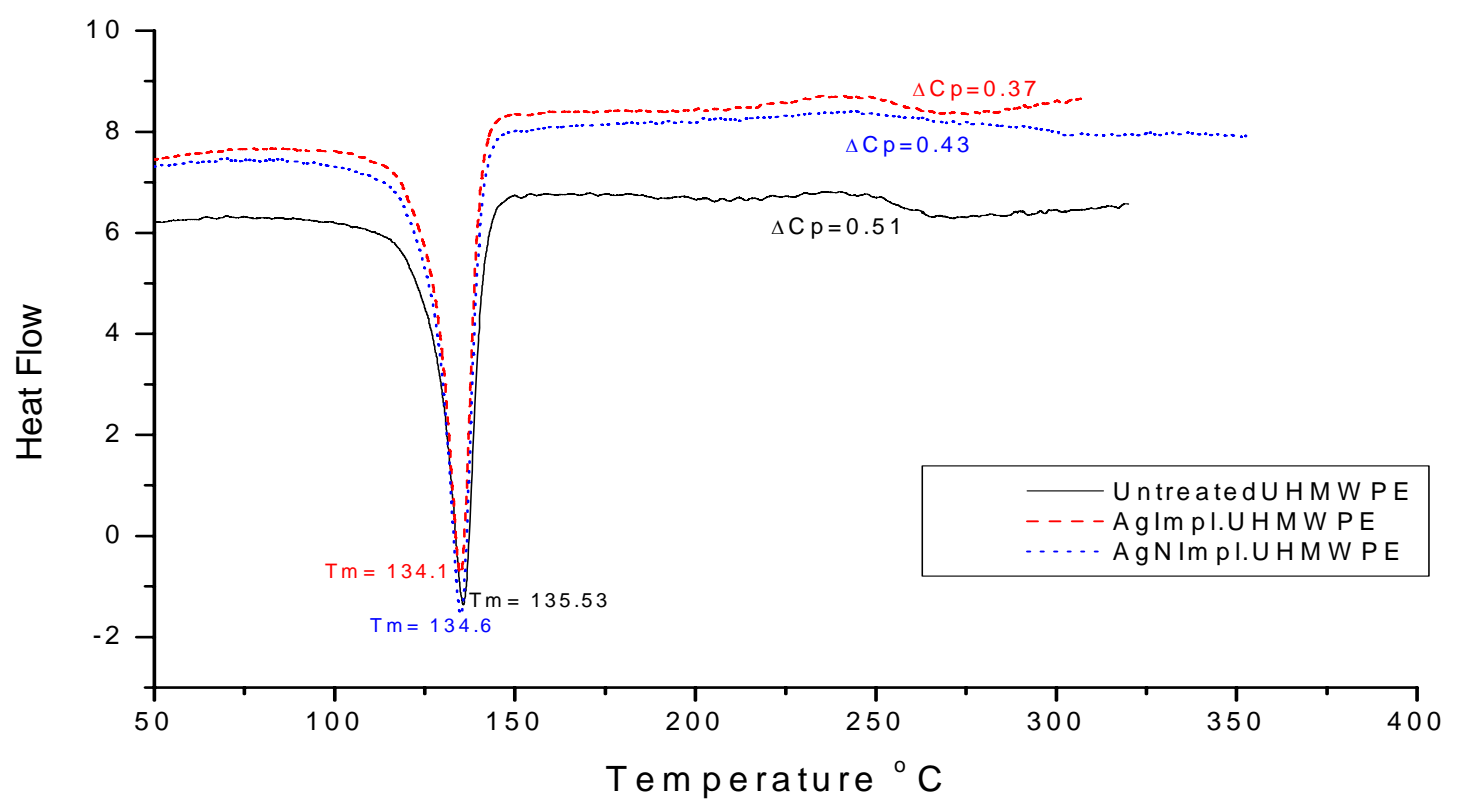

Figure . 8. TGA curves of the samples of UHMWPE before and after the ion implantation with $\mathrm{C}+\mathrm{H}, \mathrm{C}+\mathrm{H}+\mathrm{Ar}$ ions.

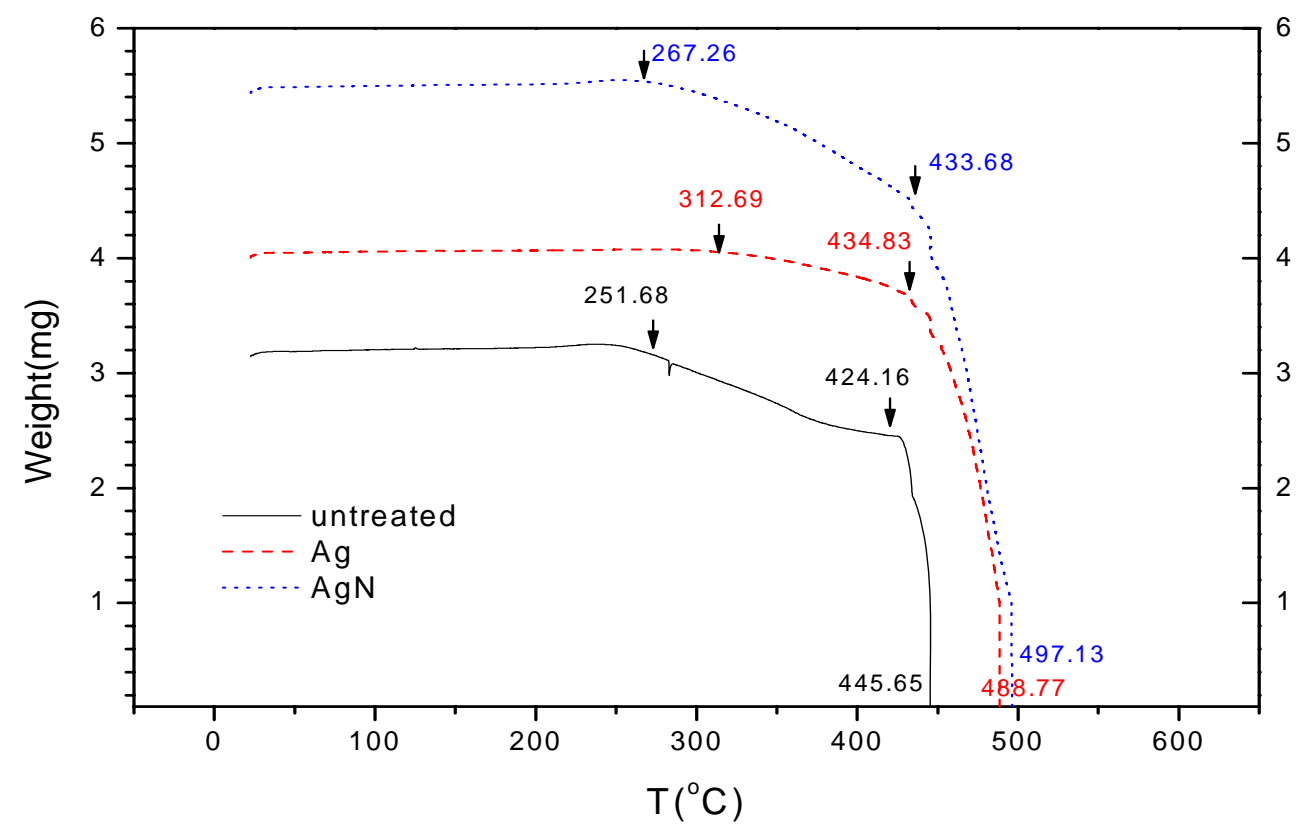

Figure .9. TGA Analysis of Untreated, $\mathrm{Ag}$ and $\mathrm{Ag}+\mathrm{N}$ Implanted UHMWPE Samples.

In TGA results, onset of degradation starts for untreated UHMWPE is $251.68{ }^{\circ} \mathrm{C}$. This point shifted after irradiation to higher values for implanted samples (Figures 8,9 ). With 
the same trend total degradation point $424{ }^{0} \mathrm{C}$ for untreated UHMWPE sample shifted to higher values for implanted samples. These results can indicate that the thermal stability increased at the surface [8]. Shore-D hardness measurements of unimplanted and implanted UHMWPE samples are given in Table.1, which shows that hardness increases with ion implantation. Hardness is purely a relative term and an increase in hardness is due to the crosslink formation on the surface $[9,10]$. It was also observed that $\mathrm{C}-\mathrm{H}$ bond concentration seemed to be decreasing. This might also indicate that $\mathrm{C}$ rich surfaces and graphite like structures occurred, resulting in increased hardness.Contact angle and roughness results are given in Table. 2 . It seems that the wettability increased with ion implantation and that hidroxil bonds and carbonil bonds have dominant effect on wettability. Rather low contact values for $\mathrm{Ag}+\mathrm{N}$ could be due to formation of nitride which has an additional effect to oxygen containing groups.

\begin{tabular}{|l|l|l|l|l|l|l|l|}
\hline $\begin{array}{l}\text { Contact } \\
\text { Angle }\end{array}$ & UHMWPE & $\mathrm{Ag}$ & $\mathrm{Ag}+\mathrm{N}$ & $\mathrm{C}+\mathrm{H}$ & $\mathrm{C}+\mathrm{H}+\mathrm{Ar}$ & $\mathrm{Ti}+\mathrm{O}$ & $\mathrm{Ti}+\mathrm{Al}+\mathrm{N}$ \\
\hline Water & $\mathbf{5 6 . 2 ^ { \circ }}$ & $\mathbf{4 4 . 8 ^ { \circ }}$ & $\mathbf{3 2}^{\circ}$ & $\mathbf{3 7 . 5}$ & $\mathbf{4 7 . 5}$ & $\mathbf{3 0}^{\circ}$ & $\mathbf{4 8}^{\circ}$ \\
\hline
\end{tabular}

Table. 2 Contact angle measurements with water.

Figure. 10. shows the surface topography of unimplanted and implanted UHMWPE samples obntained by AFM. As seen from the figure surface roughness decreases with ion implantation. This is probably due to rapid melting of the polymer surfaces as a result of ion irradiation. High roughness of $\mathrm{C}+\mathrm{H}+\mathrm{Ar}$ implanted UHMWPE surface could be due to Ar ion sputtering.
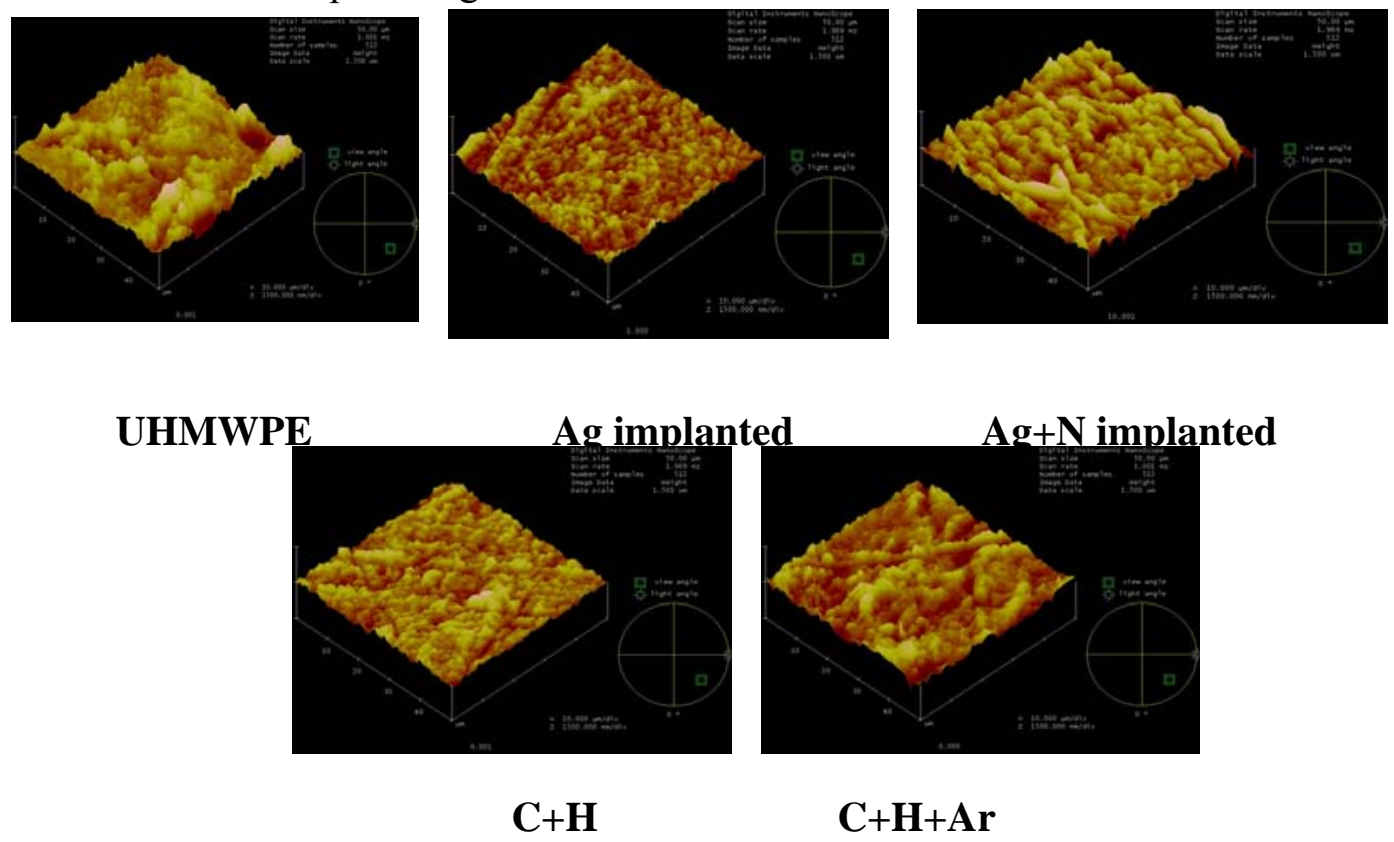

Figure. 10. Surface topography of unimplanted and implanted UHMWPE samples obntained by AFM. 
SEM micrographs of unimplanted, $\mathrm{Ag}$ and $\mathrm{Ag}+\mathrm{N}$ implanted UHMWPE surfaces were obtained randomly with several measurements are shown in figure 11 . Results represent the surface morphology of UHMWPE before and after implantation. Cracks on the surface are significantly disappeared after $\mathrm{Ag}$ and $\mathrm{Ag}+\mathrm{N}$ implantation. Especially, cracks were totally disappeared with Ag implantation.

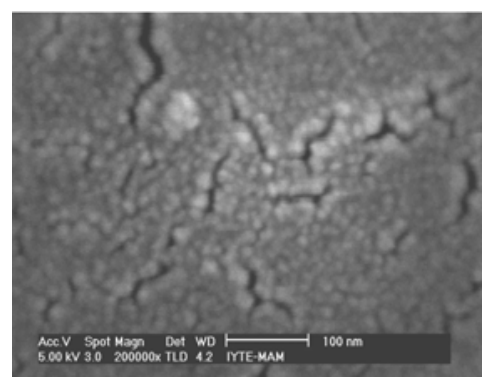

(a)

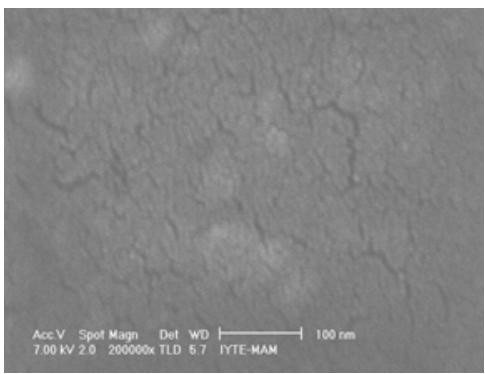

(b)

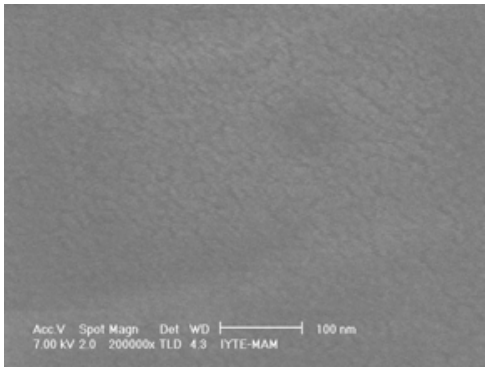

(c)

Figure 11. SEM micrographs of (a) unimplanted, (b) $\mathrm{Ag}+\mathrm{N}$ implanted and (c) $\mathrm{Ag}$ implanted UHMWPE samples.

The results proved the Antibacterial effect of Ag implanted in UHMWPE, however, the measurements should be repeated after the wear tests.

\section{Conclusion}

The results indicated that the chain structure of UHMWPE were changed and crosslink density increased. There was slight increase in percentage crystallinity but decrease in melting point $T_{m}$ with irradiation, which may be due to the chain sission of UHMWPE since $\mathrm{T}_{\mathrm{m}}$ is closely related to number average molecular weight and also $\mathrm{C}=\mathrm{C}$ double bond formation as seen in FTIR spectra.

It is believed that slight increase in the crystallinity of the polymer may improve the surface quality of the polymers such as hardness, wear resistance and wettability. It was also observed that $\mathrm{C}-\mathrm{H}$ bond concentration seemed to be decreasing. This might indicate that $\mathrm{C}$ rich surfaces and graphite like structures occurred, resulting in increased hardness. It was observed that nano size cracks (approx.10nm) significantly disappeared after $\mathrm{Ag}$ implantation, however less significant with $\mathrm{Ag}+\mathrm{N}$ implantation . This is probably due to rapid melting of the polymer surfaces as a result of ion irradiation, which was also thought to be responsible for decreasing in roughness. Contact angle measurements showed that wettability of samples increased with ion implantation. It is thought that increased in oxygen concentration and formation of carbonyl groups were responsible for this. Rather low contact values for $\mathrm{Ag}+\mathrm{N}$ could be due to formation of nitride which has an additional effect to oxygen containing groups. Results indicate that metal and metal+gas hybrid ion implantation could be an effective way to improve the surface of UHMWPE together with antibacterial effect of $\mathrm{Ag}$ implantation. 


\section{Acknowledgements}

This work was supported by the Center for Irradiation of Materials, Alabama A\&M University.

\section{List of References}

1. E. M. Oks, G. Yu.Yushkov, P.J.Evans, A.Oztarhan, I.G.Brown, M.R.Dickinson, F.Liu, R.A. MacGill, O.R. Monteiro and Z.Wang, "Hybrid gas-metal co-implantation with a modified vacuum arc ion source", Nucl. Instr. and Meth. B, Vols 127-128, pp. 782-786, 1997.

2. A. Oztarhan., I. Brown, C. Bakkaloglu, G.Watt, P. Evans, E.Oks, A. Nikolaev and Z.Tek, , "Metal vapour vacuum arc ion implantation facility in Turkey", Surface and Coatings Technology, Vol 196, Issues 1-3, pp. 327-332, 2005

3. Gamma-irradiated cross-linked polyethylene in total hip replacements - analysis of retrieved sockets after long-term implantation, Hironobu Oonishi ${ }^{1{ }^{*}}$, Yoshinori Kadoya ${ }^{2}$, Shingo Masuda ${ }^{3}$, Applied Biomaterials Volume 58, Issue 2, Pages $167-171$, Published Online: 17 Jan 2001Copyright (C 2001 John Wiley \& Sons, Inc.)

4. S.M. Kurtz, The UHMWPE Handbook: Principles and Clinical applications in total joint replacement, Elsevier, Academic Press, 2004.5. Turos A., Abdul-Kader AM, Grambole D, Jagielski J, Piątkowska A, Madi NK and Al-Maadeed M, 2006, "The effects of ion bombardment of ultra-high molecular weight polyethylene", Nucl. Instr. and Meth. B, Vol. 249, Issues 1-2 , pp. 660-664

6. A.L. Evelyn, D. Ila, R.L Zimmerman, K. Bhat, D.B. Poker and Hensley, 1998, "Effects of MeV ions on PE and PVDC", Nucl. Instr. and Meth. B, Vol 141, Issues 1-4, pp. 164-168

7. P. Bracco, Brach del Prever EM, M. Cannas, M.D. Luda and L. Costa, 2006, "Oxidation behaviour in prosthetic UHMWPE components sterilised with high energy radiation in a low-oxygen environment", Polymer Degradation and Stability, Vol 91, Issue 9 , pp. 2030-20388. Marco Zanetti, Pierangiola Bracco and Luigi Costa Polymer Degradation and Stability Volume 85, Issue 1, July 2004, Pages 657-665

9. S.M. Kurtz, O.K. Muratoglu, M. Evans and A.A. Edidin, Biomaterials 20 (1999), p. 1659.

10. A. Valenza, A. M. Visco, L. Torrisi and N. Campo, Polymer, Volume 45, Issue 5 , March 2004, Pages 1707-1715. 